\title{
Engineered, Spatially Varying Isothermal Holds: Enabling Combinatorial Studies of Temperature Effects, as Applied to Metastable Titanium Alloy $\beta$-21S
}

\author{
Brian Martin ${ }^{1,2} \cdot$ Peyman Samimi $^{1,2} \cdot$ Peter Collins $^{1,2,3}$
}

Received: 1 March 2017/Revised: 20 April 2017/Accepted: 25 April 2017/Published online: 1 June 2017

(C) The Author(s) 2017. This article is an open access publication

\begin{abstract}
A novel method to systematically vary temperature and thus study the resulting microstructure of a material is presented. This new method has the potential to be used in a combinatorial fashion, allowing the rapid study of thermal holds on microstructures to be conducted. This is demonstrated on a beta titanium alloy, where the thermal history has a strong effect on microstructure. It is informed by simulation and executed using the resistive heating capabilities of a Gleeble 3800 thermomechanical simulator. Spatially varying isothermal holds of $4 \mathrm{~h}$ were affected, where the temperature range of the multiple isothermal holds varied by $\sim 175{ }^{\circ} \mathrm{C}$.
\end{abstract}

Keywords Isothermal heat treatments - Titanium alloys · Microstructure

\section{Introduction}

In recent years, there has been an increasing use of combinatorial approaches for exploration and evaluation of alloy systems [1-3]. In this context, "combinatorial” refers

Brian Martin

bmartin1@iastate.edu

Peyman Samimi

pe.samimi@gmail.com

1 Department of Materials Science and Engineering, Iowa State University, Ames, IA 50011, USA

2 Center for Advanced Non-Ferrous Structural Alloys, Joint NSF I/UCRC between the Colorado School of Mines and Iowa State University, Golden/Ames, CO/IA, USA

3 Ames Laboratory, Iowa State University, Ames, IA 50011, USA to the production of samples that cross a wide range of processing parameters or compositions to rapidly optimize for desired properties. For example, the fabrication of compositionally graded Ti-xM systems using binary powders and powder-based additive manufacturing systems allows for study of the effects of composition on properties such as high-temperature oxidation resistance $[1,2]$ or phase transformations [3]. This combinatorial approach has proven beneficial because it allows for the simultaneous assessment of large numbers of compositions (often at a fixed thermal history) without the need to produce large numbers of samples, consequently cutting the time and effort required to study the effect of composition on microstructure, properties, and performance. One of the oldest combinatorial approaches (though not identified as such) is the Jominy End Quench Test [4] which allows for rapid studies of the effect of the cooling rate on microstructure and properties. Isothermal gradients and their effects have also been studied. The effect of the heat affected zone (HAZ) in welds is one of the oldest examples of this, and still a topic of study [5]. In these cases, the HAZ is an uncontrolled, short-term heating, rather than any sort of tailored thermal gradient. Methods have been developed to induce thermal gradients via even heating in a traditional furnace, and then cooling at one end to induce a thermal gradient $[6,7]$. These techniques have been adapted to vary properties in forged nickel-based superalloy turbine disks $[8,9]$. These studies clearly show the influence of uneven thermal exposure, but are often concerned with the resulting microstructure in the finished, full sized part, with thermal monitoring limited to a few points, as well as a nonlinear thermal profile across the sample. The microstructural variation is also of note, in that the recrystallization post-forging is often the focus, where larger grains are desired in the outer rims, and smaller 
grains in the bore region $[8,9]$. In these studies, there is a sudden change in microstructure as the temperature threshold for recrystallization is crossed, rather than a gradient in features and properties to follow with the gradient in temperature. They also rely on heat flux alone, rather than any uneven heat source. While these techniques allow for the study of variations in cooling rate and aging temperature, the ability to engineer and affect thermal gradients comprised of isothermal holds in a systematic, controlled and small scale would provide a way to study more closely these thermal gradients. This is difficult to do and is rarely conducted owing to an absence of an instrumented technique to control such gradients of variable temperature isothermal holds. Presented here is an extension of these combinatorial approaches for the creation of a controlled temperature gradient within a single sample over a length scale larger than the attending microstructural features, such as grains and precipitates.

\section{Equipment and Materials}

The novel use of a Gleeble system enabled the application of a temperature gradient onto a single sample, where a $200^{\circ}$ temperature gradient can be held for a lengthy period of time. Manufactured by Dynamic Systems Inc. (DSI), the Gleeble is designed to perform a wide variety of physical simulations of thermomechanical processes [10]. The Gleeble 3800, which was used for these tests, has the capability of heating and cooling samples at highly controlled rates, all in the presence of an inert atmosphere or vacuum. The instrumented experimental technique was informed by finite element software, in the form of COMSOL Multiphysics, and the microstructure quantified using relatively new methods of quantification, namely MIPAR $^{\mathrm{TM}}$, to demonstrate this new method for rapid evaluation of isothermal holds on alloy systems.

TIMETAL $21 \mathrm{~S}$, or $\beta-21 \mathrm{~S}$, is a metastable beta titanium alloy developed for oxidation and corrosion resistance for use in aerospace applications [11]. Like all metastable beta alloys, $\beta-21 \mathrm{~S}$ retains its high-temperature $\beta$ bcc (bodycentered cubic) structure when quenched from above its beta transus of $807{ }^{\circ} \mathrm{C}$. The alloy must be aged below its beta transus in order to precipitate out the low-temperature $\alpha$ hcp (hexagonal close packed) phase to strengthen the material [12]. The exact size and distribution of these alpha precipitates strongly influence the mechanical properties and are very sensitive to the aging temperature and time [12-14]. $\beta-21 \mathrm{~S}$ is an ideal candidate alloy for verifying the novel experiment proposed here. When this alloy is exposed to a thermal gradient, a corresponding variation in microstructural features such as volume fraction of phases and feature size (e.g., $\alpha$ laths) would be expected. A plate of $\beta$-21S ( $\sim 38 \mathrm{~mm}$ thick) in the fully beta solutionized condition was provided by Timet and was used to demonstrate this new technique. The nominal chemistry of this plate, performed by Timet, is given in Table 1 .

\section{Results and Discussion}

The known phenomenon of resistive heating is the basis for this technique. The basic relationship between current $(I)$, power $(P)$, and resistance $(R)$ is given in Eq 1 .

$P \propto I^{2} R$

In physical simulators, such as the Gleeble, where resistive heating is used to heat the specimen, the current remains constant across the length of a single piece of material. Consequently, by varying the cross sectional area, and thus the resistance, the conversion from electrical energy to heat energy in that area will vary in a predictable way, allowing the Gleeble to be used as a controlled, resistive thermal gradient unit. Thus, this technique requires some sort of controlled resistive heater.

The objective of the research work is to affect an approximately linear temperature gradient with a temperature change of $\sim 200{ }^{\circ} \mathrm{C}$ across the sample. The Gleeble stainless steel hot grips were used for this study, as they not only allow for the usage of a flat sample, but also induce a more uniform thermal profile when compared with the sharper thermal profile of the more standard round copper grips [15]. The concept of the experiment was further explored using a finite element modeling approach to account for heat flow, radiation loss, and non-uniform conductive heating. Specifically, COMSOL Multiphysics was used in an exploratory manner to assess the approximate dimensions and shapes required to achieve the aforementioned criteria. Current, joule heating, and heat flow were included in the bulk sample, and boundary conditions were set for where the Gleeble grips would contact the sample on the surface. These boundary conditions had the relevant voltage drop across the sample, as well as room temperature conditions at the point of contact, to approximate the cooling of the grips.

A sample of $\beta-21 \mathrm{~S}$ was cut and machined to the final geometry (Fig. 1) from the beta solutionized plate for the verification of the proposed technique. Four K-type thermocouples were welded to the surface of the machined

Table 1 Nominal chemistry

\begin{tabular}{llllllllll}
\hline Element & $\mathrm{Mo}$ & $\mathrm{Nb}$ & $\mathrm{Fe}$ & $\mathrm{Si}$ & $\mathrm{Al}$ & $\mathrm{C}$ & $\mathrm{O}$ & $\mathrm{N}$ & $\begin{array}{l}\mathrm{H} \\
(\mathrm{ppm})\end{array}$ \\
\hline wt.\% & 15.0 & 2.6 & 0.3 & 0.21 & 3.1 & 0.02 & 0.14 & 0.01 & 83 \\
\hline
\end{tabular}




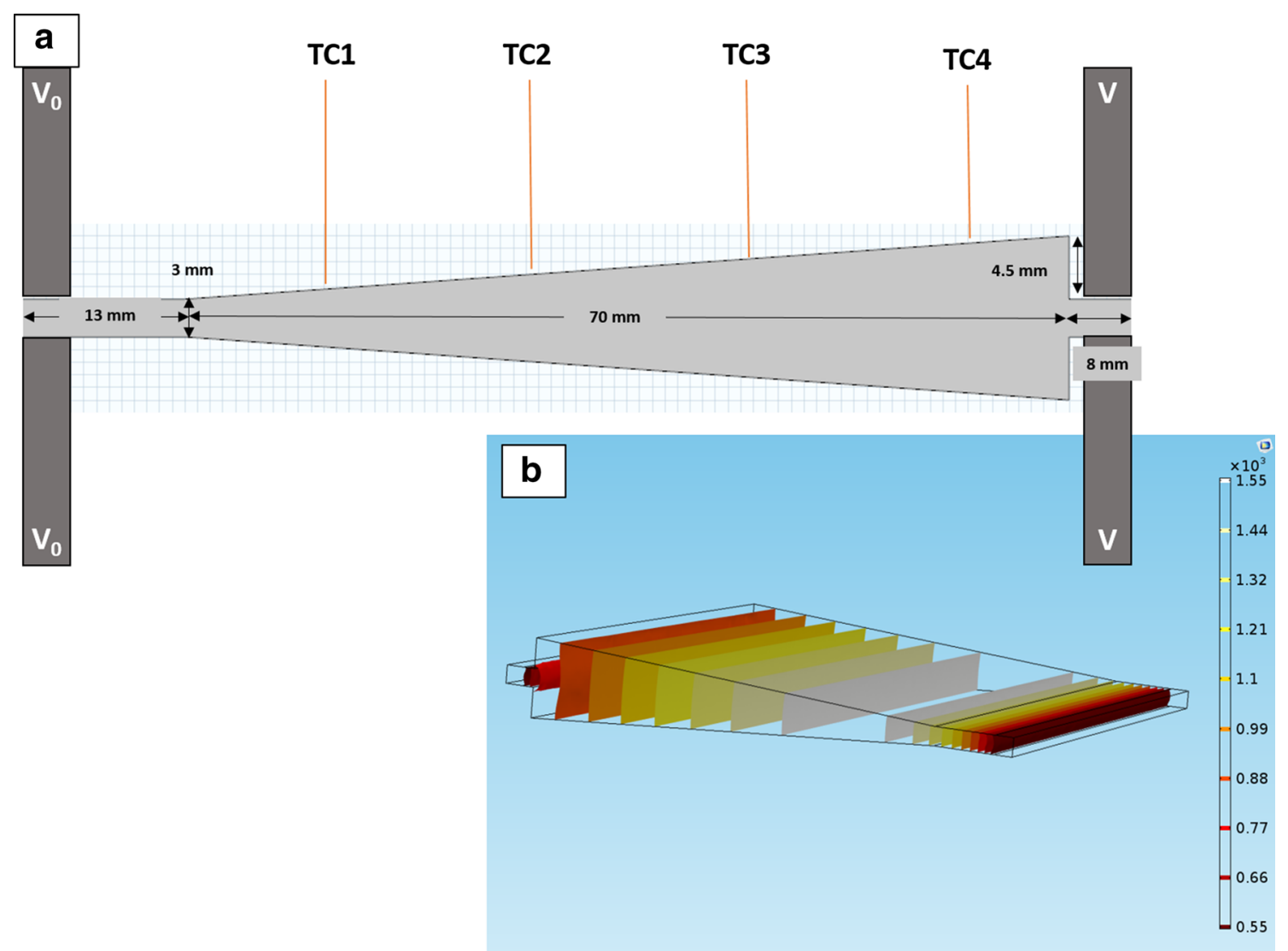

Fig. 1 (a) Schematic of the experimental design, showing dimensions of the sample, location of thermocouples, and points of contact for the grips, which provide current as well as cooling. (b) Graphic of

sample for the purposes of monitoring and controlling the temperature along the sample, as marked in Fig. 1a. To avoid oxidation on the sample, the Gleeble test chamber was rough pumped and backfilled with argon 3 times, then diffusion pumped to $2.6 \times 10^{-5}$ torr. The controlling thermocouple was positioned at the narrowest point, where the temperature would be the highest. The controlling set point of this position was $700{ }^{\circ} \mathrm{C}$. Given that the stainless steel grips do not allow for the same rapid ramping up of temperature that the copper grips do, the sample was heated over $3 \mathrm{~min}$. The other three thermocouples were allowed to come to temperature and monitored to determine when the temperatures reached a steady state (Fig. 2). The specimen was held at the spatially graded isothermal holds for $4 \mathrm{~h}$ to allow the microstructure to reach a reasonable degree of equilibrium.

Following the Gleeble experiment, the sample was cut along the center line, cold mounted and polished with $0.04 \mu \mathrm{m}$ colloidal silica as a single piece, and imaged using an FEI Quanta 250 FE-SEM in backscatter mode. Images were taken along the points where the thermocouple was taking direct measurements, shown in Fig. 3. This was done simply to verify that the expected variation in the COMSOL model, showing the isothermal surfaces, perpendicular to the current flow

microstructure followed the change in aging temperature. As expected, there was a marked variation in the microstructure as the aging temperature increased from 527 to $700{ }^{\circ} \mathrm{C}$. As the temperature increased, the alpha phase stability drops, and the volume fraction of alpha naturally declines. A quantitative analysis of the volume fraction of the $\alpha$ phase at various points was done using $\operatorname{MIPAR}^{\mathrm{TM}}$, a new and powerful image processing software package [16]. Using adaptive thresholding, MIPAR ${ }^{\mathrm{TM}}$ is able to automatically differentiate features in an image for quantification, and apply the same procedures automatically to an entire batch of images for rapid acquisition of a large amount of microstructural data. As expected, the volume fraction of alpha declines with increasing temperature, and the microstructure transitions from a refined basket weave microstructure consisting of interpenetrating $\alpha$ laths, to coarse, discrete $\alpha$ particles dispersed in the $\beta$ matrix. Usually, the finer scaled $\alpha$ phase is desired for the increased hardness and strength, and much work has been done to engineer finer scale structures in $\beta-21 S[13,17]$. To show this change in mechanical properties across this thermally graded sample, a rudimentary assessment was conducted by measuring the Vickers microhardness at the four points 

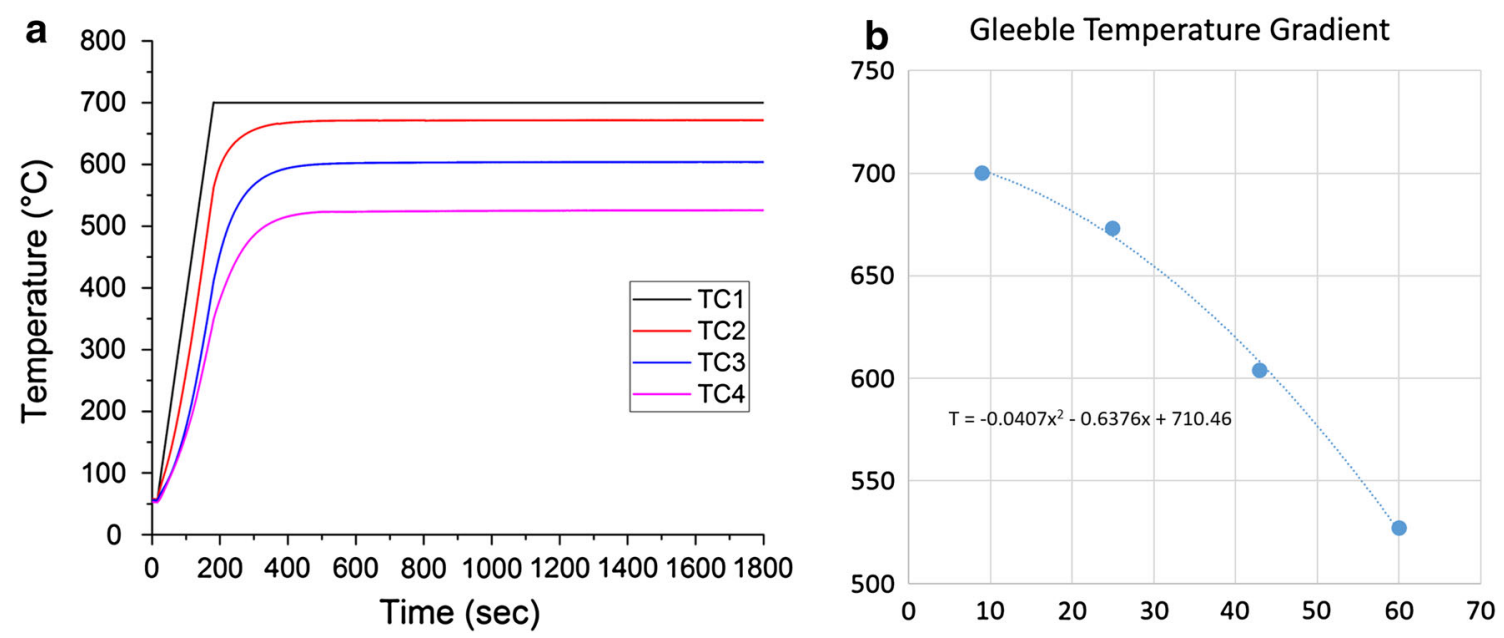

Fig. 2 Thermal data, taken from the thermocouple readouts on the Gleeble. (a) Plot of thermocouple readouts, showing the heating of the sample and the steady-state temperatures. (b) Plot of the steady-state temperatures along the length of the sample, fitted to a quadratic function
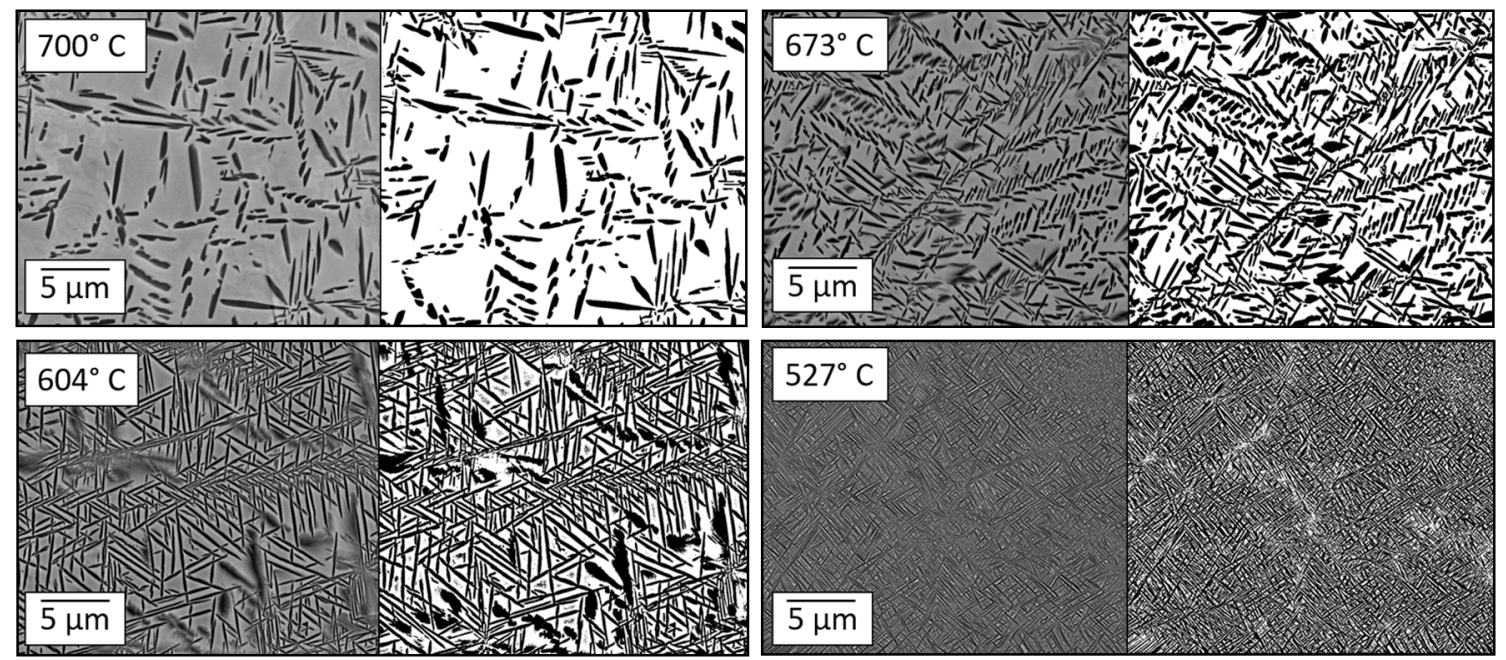

Fig. 3 SEM backscatter images at the points of interest in the $4 \mathrm{~h}$ thermally graded $\beta-21 \mathrm{~S}$, next to the MIPAR images post processed to calculate the phase fractions. The changes in microstructure seen as the aging temperature changes are expected for these metastable $\beta$ titanium alloys

Table 2 Mechanical properties

\begin{tabular}{lclll}
\hline & $X(\mathrm{~mm})$ & $T\left({ }^{\circ} \mathrm{C}\right)$ & Hardness & Volume fraction $\alpha$ \\
\hline A & 9 & 700 & $298.1 \pm 6.1$ & $0.27 \pm 0.04$ \\
B & 25 & 673 & $329.4 \pm 12.1$ & $0.37 \pm 0.04$ \\
C & 43 & 604 & $369.8 \pm 8.4$ & $0.52 \pm 0.03$ \\
D & 60 & 527 & $442.2 \pm 10.6$ & $0.62 \pm 0.05$ \\
\hline
\end{tabular}

of interest. A summary of these characterization efforts is presented in Table 2.

While there is the potential for much more characterization work on this sample, including the examination of the prior beta grain size and the regions between these four locations, the characterization work presented here is enough to demonstrate the viability of this procedure.

\section{Conclusion}

This method represents the next step in combinatorial materials science. Through the use of the Gleeble, and a carefully designed geometry, it has been shown that a gradient of temperatures can be induced in a single metal sample. Simulation techniques, such as COMSOL, can be used to guide the design of the geometry for the desired temperature gradient. $\beta-21 \mathrm{~S}$ was an ideal candidate to demonstrate this technique, owing to its sensitivity to aging temperature and the effect this has on the mechanical properties. While this method was verified with microstructural characterization and microhardness, this entirely new technique clearly has broad impact to materials process research. The ability to construct and hold a thermal gradient across such a small specimen further 
shows the usefulness and increasing viability of combinatorial metallurgy.

Acknowledgments The authors gratefully acknowledge the support of the Center for Advanced Non-Ferrous Structural Alloys (CANFSA), a National Science Foundation Industry/University Cooperative Research Center (Grant \# 1624748), material provided by Timet, support under the $\mathrm{Al}$ and Julie Renken Professorship at Iowa State University, and the Materials and Analysis Research Laboratory (MARL) at Iowa State University.

Open Access This article is distributed under the terms of the Creative Commons Attribution 4.0 International License (http://crea tivecommons.org/licenses/by/4.0/), which permits unrestricted use, distribution, and reproduction in any medium, provided you give appropriate credit to the original author(s) and the source, provide a link to the Creative Commons license, and indicate if changes were made.

\section{References}

1. P. Samimi, Y. Liu, I. Ghamarian, P.C. Collins, A novel tool to assess the influence of alloy composition on the oxidation behavior and concurrent oxygen-induced phase transformations for binary Ti-xMo alloys at $650{ }^{\circ} \mathrm{C}$. Corros. Sci. 89, 295-306 (2014)

2. P. Samimi, Y. Liu, I. Ghamarian, D.A. Brice, P.C. Collins, A new combinatorial approach to assess the influence of alloy composition on the oxidation behavior and concurrent oxygen-induced phase transformations for binary $\mathrm{Ti}-\mathrm{xCr}$ alloys at $650^{\circ} \mathrm{C}$. Corros. Sci. 97, 150-160 (2015)

3. R. Banerjee, S. Nag, H.L. Fraser, A novel combinatorial approach to the development of beta titanium alloys for orthopaedic implants. Mater. Sci. Eng. C 25(3), 282-289 (2005)

4. ASTM A255 (2014)
5. Y. Hanghang, Y. Zekun, G. Jun, G. Hongzhen, L. Yingying, W. Min, Influence of gradient heat treatment on microstructure and microhardness in weld seam of $\mathrm{Ti}_{3} \mathrm{Al} / \mathrm{TC} 11$ dual alloys. Rare Met. Mater. Eng. 39(1), 22-26 (2010)

6. A. Tejfalussy, Temperature distribution regulating sample holderadapter for forming conditions for gradient heat treatment in heat treatment ovens or furnaces, 4,609,343, 1986

7. J. Gayda, T. Gabb, P. Kantzo, Heat treatment devices and method of operation thereof to produce dual microstructure superalloy disks, US 6,660,110 B1, 2003

8. G. Tian, C. Jia, J. Liu, B. Hu, Experimental and simulation on the grain growth of $\mathrm{P} / \mathrm{M}$ nickel-base superalloy during the heat treatment process. Mater. Des. 30(3), 433-439 (2009)

9. Y. Ning, Z. Yao, H. Guo, M.W. Fu, Structural-gradient-materials produced by gradient temperature heat treatmentfor dual-property turbine disc. J. Alloys Compd. 557, 27-33 (2013)

10. S.T. Mandziej, Physical simulation of metallurgical processes. Mater. Technol. 44(3), 105-119 (2010)

11. R.R. Boyer, An overview on the use of titanium in the aerospace industry. Mater. Sci. Eng. A 213, 103-114 (1996)

12. G. Lütjering, J. Williams, Titanium (Springer, Berlin, 2007)

13. S.A. Mantri, D. Choudhuri, A. Behera, J.D. Cotton, N. Kumar, R. Banerjee, Influence of fine-scale $\alpha$ precipitation on the mechanical properties of the beta titanium alloy $\beta$-21S. Metall. Mater. Trans. A 46(7), 2803-2808 (2015)

14. I. Weiss, S.L. Semiatin, Thermomechanical processing of beta titanium alloys—an overview. Mater. Sci. Eng. A 243(1), 46-65 (1998)

15. Dynamic Systems Incorporated, Gleeble Users Training, Poestenkill, 2015

16. J.M. Sosa, D.E. Huber, B. Welk, H.L. Fraser, Development and application of MIPAR ${ }^{\mathrm{TM}}$ : a novel software package for two- and three-dimensional microstructural characterization. Integr. Mater. Manuf. Innov. 3, 10 (2014)

17. S. Ankem, C. Greene, Recent developments in microstructure/ property relationships of $\beta$ titanium alloys. Mater. Sci. Eng. A 263(2), 127-131 (1999) 